\title{
Hemodynamic and Metabolic Parameters During Prolonged Cardiac Arrest and Reperfusion by Extracorporeal Circulation
}

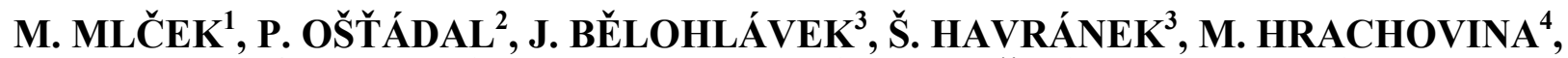 \\ M. HUPTYCH ${ }^{4}$, P. HÁLA ${ }^{1}$, V. HRACHOVINA ${ }^{1}$, P. NEUŽIL ${ }^{2}$, O. KITTNAR $^{1}$ \\ ${ }^{1}$ Department of Physiology, First Faculty of Medicine, Charles University in Prague, Czech \\ Republic, ${ }^{2}$ Department of Cardiology, Na Homolce Hospital, Prague, Czech Republic, ${ }^{3}$ Second \\ Department of Medicine, First Faculty of Medicine, Charles University in Prague, Czech Republic, \\ ${ }^{4}$ Department of Cybernetics, Faculty of Electrical Engineering, Czech Technical University, Prague, \\ Czech Republic
}

Received May 7, 2012

Accepted August 19, 2012

\section{Summary}

Extracorporeal membranous oxygenation (ECMO) is increasingly used in the management of refractory cardiac arrest. Our aim was to investigate early effects of ECMO after prolonged cardiac arrest. In fully anesthetized swine $(48 \mathrm{~kg}, \mathrm{~N}=18)$ ventricular fibrillation (VF) was induced and untreated period (20 min) of cardiac arrest commenced, followed by 60 min extracorporeal reperfusion (ECMO flow $100 \mathrm{ml} / \mathrm{kg} . \mathrm{min}$ ). Hemodynamics, arterial blood gasses, plasma potassium, tissue oximetry $\left(\mathrm{StO}_{2}\right)$ and cardiac (EGM) and cerebral (BIS) electrophysiological parameters were continuously recorded and analyzed. Within 3 minutes of VF hemodynamic and oximetry parameters fall abruptly while metabolic parameters destabilize gradually over 20 minutes peaking at $\mathrm{pH} 7.04 \pm 0.05, \mathrm{pCO}_{2}$ $89 \pm 14 \mathrm{mmHg}, \mathrm{K}^{+} 8.5 \pm 1.6 \mathrm{mmol} / \mathrm{l}$. During reperfusion most parameters restore rapidly: within 3-5 minutes mean arterial pressure reaches $>40 \mathrm{mmHg}, \mathrm{StO}_{2}>50 \%, \mathrm{paO}_{2}>100 \mathrm{mmHg}$, $\mathrm{pCO}_{2}<50 \mathrm{mmHg}, \mathrm{K}^{+}<5 \mathrm{mmol} / \mathrm{l}$. EGMs mean amplitude peaks at $4.5 \pm 2.4 \mathrm{~min}$. Cerebral activity (BIS>60) reappeared in 5 animals after $87 \pm 21 \mathrm{~min}$. In $12 / 18$ animals return of spontaneous circulation was achieved. In conclusions, ECMO provides rapid restitution of internal milieu even after prolonged arrest. However, despite normalization of global parameters full recovery was not guaranteed since cardiac and cerebral electrical activities were sufficiently restored only in some animals. More sensitive and organ specific indicators need to be identified in order to estimate adequacy of cardiac support devices.

\section{Key words}

Prolonged heart arrest • Ventricular fibrillation - Extracorporeal membrane oxygenation $\bullet$ Extracorporeal life support $\bullet$ Reperfusion

\section{Corresponding author}

Mikulas Mlcek, Charles University in Prague, First Faculty of Medicine, Department of Physiology, Albertov 5, 12800 Prague 2, Czech Republic. E-mail: mikulas.mlcek@staff.cuni.cz

\section{Introduction}

Despite advances in medical care, education and technologies, out-of-hospital cardiac arrest (OHCA) remains an important cause of unexpected death with a very low survival rate (cca 4-14\%) that remains unchanged past decades (Sasson et al. 2010). Urgent deployment of cardiopulmonary bypass (Fig. 1), i.e. extracorporeal heart-lung machine, is a promising strategy that has been proven to revert otherwise fatal prognosis of refractory cardiac arrest (not responding to treatment within $30 \mathrm{~min}$ ) (Massetti et al. 2005). However, several clinical and experimental studies report significantly different results in terms of reduced mortality and improved neurological outcome in extracorporeal support setup (Massetti et al. 2005, Fredriksson et al. 2010, Kagawa et al. 2010, Avalli et al. 2012, Le Guen et al. 2011). This is a consequence of heterogeneous experimental/clinical conditions, specifically etiology, the duration of no-flow/low flow circulation (Weisfeldt and Becker 2002, Fredriksson et al. 2010), hypothermia protocol, etc. Thus, optimal deployment strategies, risk stratification and prognostic markers remain to be identified so that patients could benefit from novel technologies but also that futile efforts are avoided. 


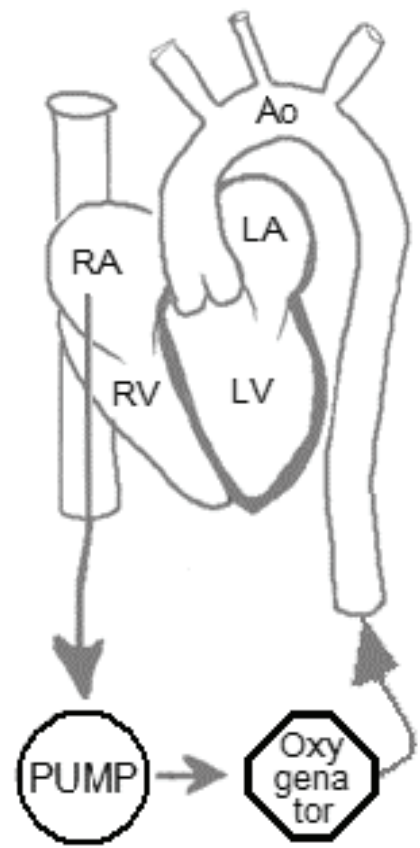

Fig. 1. ECMO Circuit Scheme. Centrifugal pump (PUMP) sucks blood from right atrium (RA) via inlet cannula. Then, blood is forced through membranous oxygenator and ejected via outlet cannula into descending aorta (Ao). Blood flow is continuous and in most of aorta of reversed direction compared to physiological conditions.

In the present study, the time-course of metabolic and electrophysiological changes was explored during $20 \mathrm{~min}$ minimal-flow cardiac arrest and subsequent early reperfusion period (60 minutes) treated by extracorporeal circulation in a swine biomodel. We hypothesize that despite a long period of untreated arrest an early ECMO deployment can significantly improve metabolic and organ condition and thus resuscitability. The results should provide some guides that would enable exploration and optimization of novel therapies for prolonged cardiac arrest.

\section{Materials and Methods}

The protocol (Fig. 2A) was designed to simulate possible future treatment strategy of CA: Initial 20minutes long minimal-flow cardiac arrest represents OHCA that is untreated and poorly treated by lay rescuers. Subsequently, full reperfusion is provided by extracorporeal life support (heart-lung bypass device, pharmacotherapy) that represents a novel therapeutic approach applicable already nowadays by highly specialized resuscitation team.

The experimental protocol was approved by the institutional Animal Expert Committee of Charles
University. All procedures were performed in accredited University experimental laboratory. Cross-bred swine (Landrace $\mathrm{x}$ White), $\mathrm{n}=18$, female, $48 \pm 1.9 \mathrm{~kg}$ were used.

\section{Anesthesia and monitoring}

Following anesthesia induction (azaperone 2-3 mg/kg, atropine $10 \mu \mathrm{g} / \mathrm{kg}$, ketamine $20 \mathrm{mg} / \mathrm{kg}$ all i.m.) and preparation, a venous cannula was inserted into marginal ear vein and anesthesia was induced by propofol bolus $(2 \mathrm{mg} / \mathrm{kg}$ ). The pigs were provided with $100 \%$ oxygen via a facial mask, orotracheal intubation was performed, and total intravenous anesthesia commenced (propofol 6-12 mg/kg.h, morphin 0.1-0.2 mg/kg.h). Mechanical ventilation was adjusted by Intellivent-ASV closed-loop system (G5, Hamilton Medical, Bondauz, Switzerland) to maintain target $\mathrm{EtCO}_{2}$ at $38-42 \mathrm{mmHg}$. Invasive blood pressures - systemic arterial, pulmonary artery, CVP (TruWave, Edwards Lifesciences, USA), ECG, capnography, pulse oximetry, rectal temperature and Bispectral index (BIS) of cerebral electrical activity (Sigl and Chamoun 1994) were continuously monitored by patient monitor (Life Scope TR, Nihon Kohden, Japan). Due to technical constraints EEG/BIS were successfully recorded only in 12/16 animals. Peripheral tissue oxygen saturation $\left(\mathrm{StO}_{2}\right)$ levels were measured by near infrared spectroscopy (NIRS) using an INVOS ${ }^{\circledR}$ Cerebral/Somatic Oximeter (Somanetics Corporation, Troy, MI, USA). The sensor was attached to the forehead. Mixed venous oximetry $\left(\mathrm{SvO}_{2}\right)$, continuous cardiac output (CCO) and pulmonary artery temperature were recorded by Swan-Ganz Combo V cathether (Vigilance monitor, Edwards Lifesciences, USA). Diagnostic decapolar catheter (Response CSL, St. Jude Medical, USA) was inserted into the right ventricle (RV) via jugular vein to induce $\mathrm{VF}$ and to monitor intracardial electrograms (EGMs). 5 bipolar channels were recorded from apex to base of $\mathrm{RV}$ at $3 \mathrm{kHz}$ sampling rate.

Cardiopulmonary bypass (CPB) (Fig. 1) was established prior to the arrest: an inlet $21 \mathrm{~F}$ cannula was inserted via femoral vein into right atrium, and an outlet $15 \mathrm{~F}$ cannula into abdominal aorta via femoral artery. The cannulae were connected to form the circuit with a blood pump (Levitronix Centrimag, Levitronix, USA) and oxygenator (Quadrox, Maquet, Germany), constituting an ECMO system. Circuit was primed with $300 \mathrm{ml}$ of normal saline and Heparin $5 \mathrm{IU} / \mathrm{ml}$. Blood gasses, $\mathrm{pH}$ and potassium were continuously sampled in ECMO circuit and recorded by real-time analyzer (CDI 500, Terumo, Japan). 


\section{A}
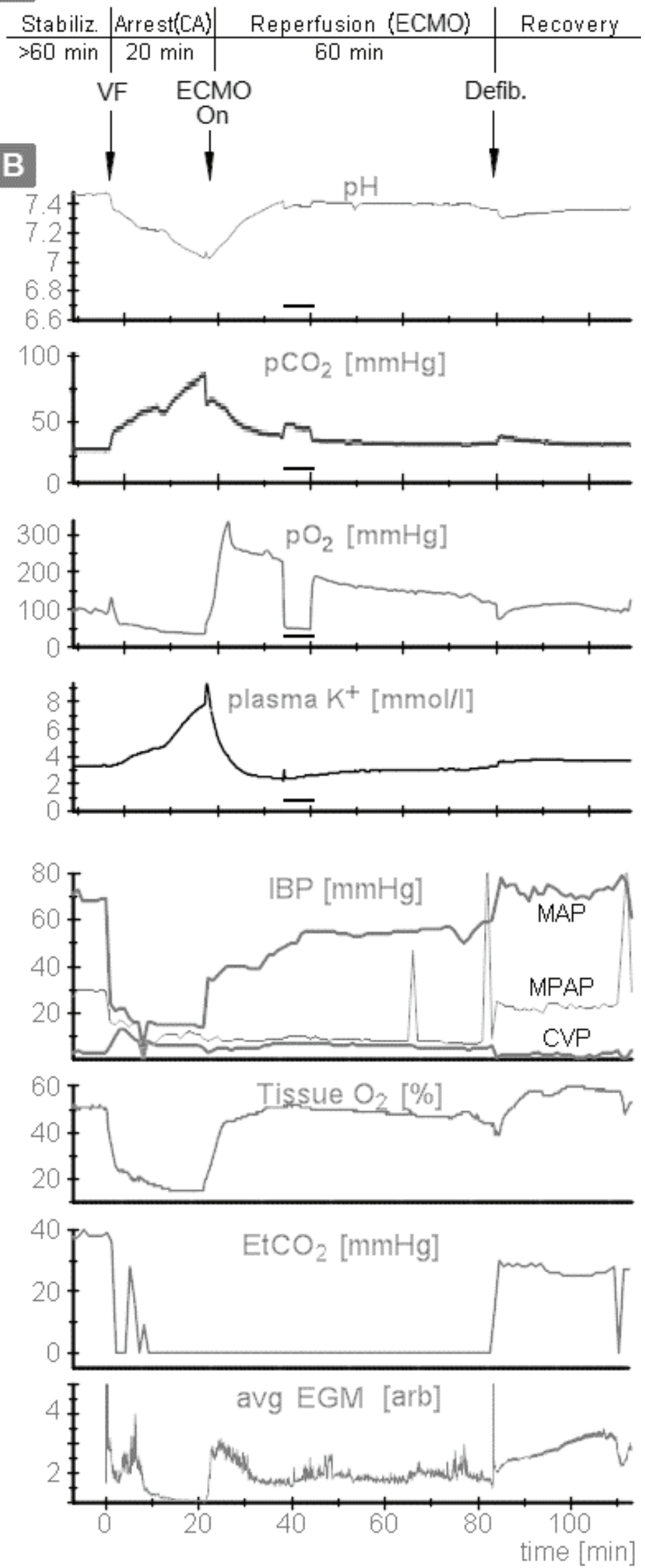

Fig. 2. Protocol outline (A) and sample trend data (B) during CA and reperfusion. Time axes for panel $A$ and $B$ are synchronized. A: After stabilization, VF triggers 20-minutes cardiac arrest (CA) period. Then 60-minutes reperfusion phase (ECMO) follows after which defibrillation (Defib) attempts were made. B: Detailed sample trend data from animal \#6 are presented to illustrate rapid changes after $\mathrm{VF}$ and ECMO and their relationship. $\mathrm{pH}, \mathrm{pCO}_{2}, \mathrm{pO}_{2}, \mathrm{~K}^{+}$were obtained from blood leaving oxygenator (excluding short period indicated by horizontal line around 40 minutes post arrest at which venous blood was sampled). IBP - invasive blood pressure, MAP - mean arterial pressure, MPAP - mean pulmonary artery pressure, CVP - central venous pressure. Avg EGM represents mean amplitude of myocardial electrical activity. Note a transient peak in $\mathrm{EtCO}_{2}$ trace $\sim 5$ minutes after VF onset which is attributed to period of gasping. At the same time a peak in myocardial electrical activity (EGM) is recorded. No other traces seem to reflect this event. 


\section{Protocol (Fig. 2A)}

The baseline data were recorded for minimum of 60 minutes after anesthesia induction. Then, ventricular fibrillation was induced (time $\mathrm{T}=0$ ) by right ventricle rapid pacing $(4 \rightarrow 5 \mathrm{~Hz}, 12 \mathrm{~s}$ duration, stimulation current twice above the pacing threshold) followed by 20-minutes of untreated cardiac arrest. ECMO flow was reduced to $10 \mathrm{ml} / \mathrm{kg} \cdot \mathrm{min}$ (referred to as minimal flow) with no oxygenation. Minimal flow allowed for continuous blood sampling and was necessary to prevent coagulation in extracorporeal circuit. Mechanical ventilation was suspended throughout the arrest and reperfusion period. At $\mathrm{T}=20 \mathrm{~min}$, reperfusion phase was initiated by gradual increase of ECMO flow to $100 \mathrm{ml} / \mathrm{kg} \cdot \mathrm{min}$ and the oxygenator air flow to $100 \mathrm{ml} / \mathrm{kg} \cdot \mathrm{min}, \quad \mathrm{FiO}_{2}=1.0$. Subsequent therapeutic interventions included: sodium bicarbonate $2 \mathrm{mmol} / \mathrm{kg}$, norepinephrine $(0.5-$ $1.5 \mu \mathrm{g} / \mathrm{kg} . \mathrm{min})$ titrated to maintain mean arterial pressure $\mathrm{MAP} \geq 60 \mathrm{mmHg}$, oxygenator air flow to maintain $\mathrm{p}_{\mathrm{a}} \mathrm{CO}_{2}$ $35-45 \mathrm{mmHg}$. $\mathrm{FiO}_{2}$ was reduced as needed. At $\mathrm{T}=80 \mathrm{~min}$, defibrillation was performed by a biphasic $200 \mathrm{~J}$ countershock (TEC-5521, Nihon Kohden, Japan), repeated as needed. Return of spontaneous circulation (ROSC) was confirmed if pulsatile arterial pressure was obtained and respective animals were considered short time survivors.

\section{Outcome evaluation}

Hemodynamic trends and real-time blood gasses were sampled at $60 \mathrm{~s}$ and $6 \mathrm{~s}$, respectively. For each group (survivors, non-survivors) the averaged values were taken at set time points: baseline, CA 1, CA 3, CA 20, ECMO 3, ECMO 5, ECMO 60. (CA = cardiac arrest, $\mathrm{ECMO}=$ extracorporeal reperfusion, numbers indicate minutes from respective phase onset.) Modified mean amplitude was used for intracardial electrograms (EGMs) analysis. Mean amplitude is one of standard VF analysis methods. In this study, the mean of 5 channels was used that helped to reduce inter-individual variability due to different intracardial electrodes positioning in right ventricles. Briefly, at each time-point the values from all 5 EGM channels were squared and added. The results were then averaged in 5-seconds intervals (15000 samples) overlapping each $2.5 \mathrm{~s}$. The results were expressed in arbitrary units instead of $\mu \mathrm{V}^{2}$.

\section{Statistics}

The data are expressed as means \pm SD. Comparison between the groups were performed using the Mann-Whitney $\mathrm{U}$ test. All $p$ values were two-tailed, $\mathrm{p}<0.05$ was considered significant. Statistical analysis was performed using SPSS 13.0 software (SPSS Inc., Chicago, IL, USA).

\section{Results}

\section{Prolonged cardiac arrest}

Following cardiac arrest, all monitored parameters deteriorate significantly (see Fig. 2B for sample traces). As expected, blood pressures drop instantly and almost equilibrate within $150 \mathrm{~s}$ (MAP $19.1 \pm 3.8 \mathrm{mmHg}$, PAP $13 \pm 1.7 \mathrm{mmHg}$, CVP $15.2 \pm 2.8 \mathrm{mmHg}$ ). At the same time peripheral tissue oxygen saturation falls to $27.6 \pm 4.9 \%$. Brain electrical activity disappears within $3.1 \pm 1 \mathrm{~min}$. Biochemical parameters change at a slower rate, almost linearly over entire arrest period peaking at 20 minutes: $\quad \mathrm{pH}=7.05 \pm 0.05 ; \quad \mathrm{pCO}_{2}=90 \pm 15 \quad \mathrm{mmHg}$; $\mathrm{paO}_{2}=16.3 \pm 8 \mathrm{mmHg} ; \mathrm{K}^{+}=8.7 \pm 1.5 \mathrm{mmol} / \mathrm{l}$.

Cardiac electrical activity (EGMs) during ventricular fibrillation provided surprisingly sensitive and timely information. Immediately after the CA onset, the mean EGM amplitude started to decline, but afterwards increased in all animals and peaked at $6.6 \pm 1.2 \mathrm{~min}$ (see Fig. 2 and Fig. 3). This local peak coincided with the period of gasping which is known to improve hemodynamics temporarily during arrest (Ristagno et al. 2007). Other parameters, however, did not record this phenomenon consistently. EGMs virtually disappeared after 18 minutes of arrest.

\section{Reperfusion}

After extracorporeal support onset (blood flow $100 \mathrm{ml} / \mathrm{kg} \cdot \mathrm{min}$ ) all monitored parameters, apart from EEG, started to restore rapidly. Dynamics of selected parameters is presented in Fig. 2. Blood pressure immediately increased, mean arterial pressure reached $\sim 40 \mathrm{mmHg}$ (MAP $38.75 \pm 6.83 \mathrm{mmHg}$ ) in 3 minutes and kept increasing at the rate $20.7 \pm 7.2 \mathrm{mmHg} / \mathrm{h}$, however continuous vasopressors administration was required. Tissue oxygen saturation $\left(\mathrm{StO}_{2}\right)$ recovered to pre-arrest levels in about $5 \min (283 \pm 80 \mathrm{~s})$ and remained stable. Plasma potassium concentration rapidly declined at the rate $1.2 \pm 0.3 \mathrm{mmol} / \mathrm{l}$.min and returned to below $5 \mathrm{mmol} / \mathrm{l}$ within 3 minutes $(187 \pm 73 \mathrm{~s})$ and then leveled off maintaining pre-arrest values. Blood $\mathrm{pH}$ returned above 7.3 in about 10 minutes $(650 \pm 134$ s). Arterial hypercapnia was almost immediately reverted by oxygenator air flow; however, significant amount of $\mathrm{CO}_{2}$ retained during arrest continued to be eliminated. 

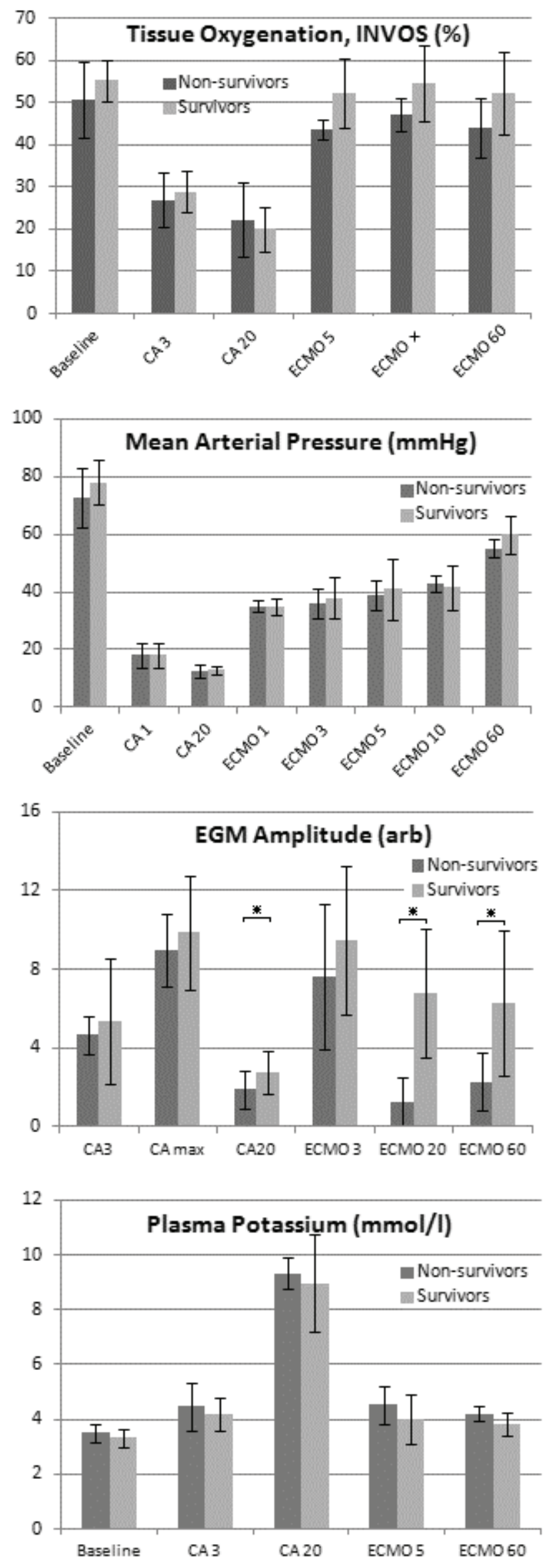

Fig. 3. Select parameters compared for survivors $(n=12)$ and nonsurivors $(n=6)$. Bars represent averages \pm SD in select time points: $\mathrm{CA}=$ untreated cardiac arrest, $\mathrm{ECMO}=$ reperfusion; numbers indicate minutes from the onset of respective period. CA max represents peak amplitude during gasping period that occurred in $\sim 6$ min of CA. Significant differences between the groups were found in EGM amplitude at the end of arrest (CA 20, $\mathrm{p}=0.044$ ) and late reperfusion phase (ECMO 20 and ECMO 60, $\mathrm{p}<0.001)$. In non-survivors EGMs reappeared after ECMO onset (ECMO 3), but decreased and virtually disappeared after 20 minutes (ECMO 20). Interestingly, all other parameters exhibited only non-significant differences between groups and some returned to normal or close-to normal levels.

Cardiac electrograms (EGMs) reappeared immediately upon the reperfusion. At about 4 minutes ( $263 \pm 127 \mathrm{~s})$ post reperfusion a prominent local maximum appeared reaching CA maximal values. It is believed to reflect coronary hyperemia due to ischemic vagoparalysis. During subsequent period, EGMs followed two alternative scenarios (Fig. 4): In $67 \%$ animals (12/18) the mean EGM amplitude stabilized or kept increasing loosely reflecting MAP trend. In all of these cases the external defibrillation at time $60 \mathrm{~min}$ of reperfusion (ECMO 60) successfully established return of spontaneous circulation (ROSC). These animals are referred to as "survivors". In $38 \%$ (6/18) animals, the mean EGM amplitude declined and disappeared in less than 20 minutes of reperfusion despite stable hemodynamics. This was a strong predictor of inability to restore spontaneous rhythm as $5 / 6$ animals stayed asystolic not responding to defibrillations and escalated ALS. Remaining one developed pulseless electrical activity resistant to treatment. These animals were considered "non-survivors".

Cerebral electrical activity recorded by twochannel EEG and BIS was successfully monitored only in 12 animals (technical reasons). EEG activity disappeared within $<2$ minutes of arrest in all animals and reappeared in $5 / 12$ animals after $87 \pm 21$ min post arrest. BIS values greater than $60 \%$ for at least 5 minutes were considered a consistent EEG recovery. Surprisingly, the recovery of cardiac and cerebral electrical activity did not correlate. In two animals EEG did appear despite VF or pulseless electrical activity. Conversely, in two ROSC animals no cerebral recovery was observed.

\section{Discussion}

We believe that 20-minutes minimal-flow cardiac arrest is a relevant model of prolonged out-ofhospital arrest of uncertain duration with inefficient help by by-standers. Unfortunately, this is still a quite common scenario. The novel approach in our study is the 

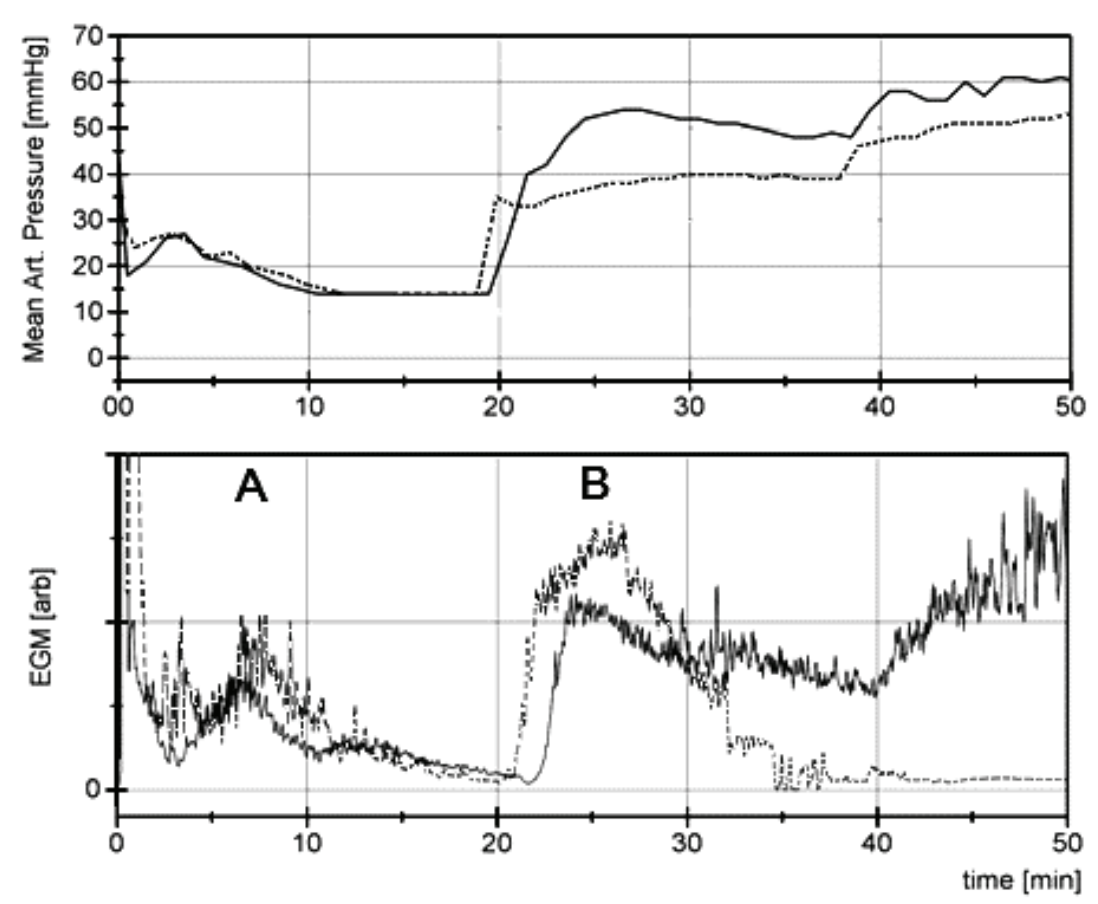

Fig. 4. Typical recordings of mean arterial pressure and mean EGM amplitude in a survivor (full) and a non-survivor (dotted) during arrest and reperfusion. CA onset at $\mathrm{T}=0 \mathrm{~min}, \mathrm{ECMO}$ onset at $\mathrm{T}=20 \mathrm{~min}$. EGMs keep increasing despite overall increase in MAP. EGMs almost disappear after 15 minutes of reperfusion $(T=35)$ in nonsurvivor. Note that MAP was not statistically different among the individuals (cf. Fig. 3). In each animal, two peaks in EGMs were clearly identified: A - gasping, B reperfusion. combination of prolonged arrest followed by immediate extracorporeal reperfusion and extensive real-time monitoring. Though this protocol is unlikely to happen in current healthcare systems, the early deployment of the extracorporeal support in select cases (including out-ofhospital) is nowadays seriously discussed (Liakopoulos et al. 2010, Le Guen et al. 2011), and several cases have been reported (Lebreton et al. 2011). It has been experimentally demonstrated that hemodynamic status worsens over time during conventional ALS (Janata et al. 2008) so timely onset of cardiac support in refractory arrest is rational. However, clinical criteria for emergency ECMO are not yet established for the lack of both empirical data and robust pathophysiological understanding to ischemia-reperfusion injury in ECMO setup.

Our results indicate that despite severe metabolic and hemodynamic deterioration during prolonged cardiac arrest, restitution of adequate circulation and oxygenation can rapidly revert otherwise fatal prognosis, thus carrying a potential for dramatic improvement in survival rate. Within about 5 minutes of extracorporeal reperfusion, most monitored parameters returned to close-to-normal values $\left(\mathrm{pH}>7.3, \quad \mathrm{pCO}_{2}<50 \mathrm{mmHg}, \mathrm{K}^{+}<5 \quad \mathrm{mmol} / \mathrm{l}\right.$, $\mathrm{p}_{\mathrm{T}} \mathrm{O}_{2}>40 \%, \mathrm{MAP}>40 \mathrm{mmHg}$ ) and kept improving. In two-thirds of animals the return of spontaneous circulation (ROSC) was achieved.

Authors are convinced, that significant improvement in homeostatic parameters reflects true metabolic recovery on ECMO, not just mechanistic effect of the extracorporeal support since: (i) Oxygen extraction recovered: tissue and mixed venous oxygenation returned rapidly to the pre-arrest values $(>50 \%$ and $\sim 80 \%$ respectively) while arterial oxygen delivery was normal (provided by extracorporeal system: blood flow $100 \mathrm{ml} / \mathrm{kg} / \mathrm{min}, \mathrm{SaO}_{2}>97 \%$ ). This arterio-venous oxygen difference can only be a consequence of tissue metabolism. (ii) Stability: during one hour of extracorporeal support, all hemodynamic and metabolic parameters kept improving indicating stable homeostasis. In case of hemodynamic/metabolic deterioration ECMO and vasopressor support are known to be insufficient in maintaining perfusion pressure. (iii) Survival: in $67 \%$ of animals, spontaneous cardiac rhythm was restored after 60 minutes of extracorporeal reperfusion by 1-3 countershocks which represents exceptionally high rate considering the 20-minutes normothermic arrest. No control group without ECMO was established since it has been consistently reported that resuscitability after 15 minutes of normothermic arrest is $0-20 \%$ (Safar et al. 1990, Ao et al. 2001, Trummer et al. 2010). Repeating those results would draw ethical controversy.

Nevertheless, early recovery of global parameters that happened in all cases as discussed above did not guarantee myocardial and cerebral function restitution. In 6 of 18 animals (non-survivors) the defibrillation in 60 minutes of ECMO was unsuccessful despite reasonable hemodynamics and maximal treatment (full ECMO support, escalated ALS). Interestingly, none of the monitored parameters apart from mean EGMs 
amplitude could reliably predict the response to the defibrillation. Though EGM amplitude has proven to be very sensitive indicator of myocardial metabolism, it is rather impractical for quantitative analysis due to the nature of EGM recording. It is almost impossible to insert the catheter into a standard position in the right ventricle and obtain standard impedance. Further, the catheter displacement during defibrillation attempts cannot be avoided, thus increasing the signal variability. We failed to identify a reference value that would allow for signal normalization and thus enable direct comparison among animas. Nevertheless, because EGMs reflect cardiac metabolic changes with high sensitivity, specificity and minimal delay, improved method for cardiac electrograms analysis will be sought.

Cerebral electrical activity recorded by EEG and BIS offered rather limited information regarding neural performance. Importantly, it demonstrated relative independence of cerebral metabolism on global parameters and also independence of cerebral and myocardial recovery. It is well established, that neurons are more sensitive to ischemia then cardiac myocytes, however, neuronal recovery is a consequence of reperfusion rather than ischemic mechanisms (Madl and Holzer 2004). It has also been demonstrated, that coronary and carotid perfusion and oxygenation during ECMO can vary independently (Bělohlávek et al. 2012), being further influenced by many parameters (pulsatility, cannula position, residual cardiac output, lung oxygenation, residual autoregulation).

Significantly better myocardial recovery in our setup compared to standard ALS is in accord with a similar finding by Trummer et al. (2010) in their 15 minutes arrest and CPB model. Long, efficient extracorporeal reperfusion, compared to chest compressions and ventilation, seems to be the clue to the improved outcome since it allows for: (i) substantially better metabolic and tissue recovery prior to defibrillation attempt, and (ii) the continuation of circulatory support after the ROSC that may reduce myocardial preload and bridge dysrhythmic post-reperfusion periods.

At least two areas require further exploration: The optimal timing of counter-shock remains to be resolved. Though acidobasic parameters restore rapidly (after 5 minutes), other metabolites (e.g. oxidative stress mediators) might require considerably longer time to clear. Also blood pressure kept increasing throughout 60 minutes of reperfusion, indicating prolonged recovery of vascular tone control. Cardiac electrical activity (EGM amplitude) was maximal in $\sim 5$ minutes of reperfusion. However, this might represent a period of reactive vagolytic hyperemia during which myocytes exposure to reperfusion mediators might cause electrical instability unsuitable for defibrillation.

The other area is represented by urgent need for identification of markers specific to individual organs and tissues metabolism and perfusion since global parameters failed to predict the therapeutic outcome. Authors believe that electrophysiology parameters can provide missing information in heart and brain.

\section{Limitations}

The present model simulates clinically relevant situation to only a limited extent and the results cannot be directly translated to patients. The study was run on electrically induced VF model in young and otherwise healthy animals, fully anesthetized prior to CA while severe myocardial ischemia typically underlies ethiopathogenesis in most of cardiac arrests in adults. These facts can contribute to overall better outcome than would happen in clinical setup (Niemann et al. 2007). On the contrary, chronic ischemia may partially counterbalance the difference through the preconditioning effect.

The terms "survivors" and "non-survivors" only apply to 2-hours period of circulatory arrest and recovery and should not be extrapolated past this point nor generalized to the whole organism. For technical reasons, the temperature control prior to the $\mathrm{CPB}$ was insufficient (BT ranged $35-37{ }^{\circ} \mathrm{C}$ ) thus the recovery data include increased variability. The non-significant difference in most parameters between the groups may be the consequence of low numbers in non-survivor group.

In conclusion, fatal prognosis of prolonged cardiac arrest could be significantly improved by timely setup of full extracorporeal life support as opposed to conventional ALS. This would require both changes in current clinical recommendations and identification of reliable markers enabling early patient stratification and subsequent monitoring of organ survival.

\section{Conflict of Interest}

There is no conflict of interest.

\section{Acknowledgements}

Authors thank to Alena Ehrlichova, Karel Kypta and Tereza Vavrikova for invaluable technical and lab assistance. Supported by PRVOUK-P35/LF1/5 and SVV 2012-264504. 


$\begin{array}{llll}\text { Abbreviations } & & \text { NIRS } & \text { near infra-red spectroscopy } \\ \mathrm{ALS} & \text { advanced life support } & \text { OHCA } & \text { out-of-hospital cardiac arrest } \\ \mathrm{CA} & \text { cardiac arrest } & \text { PAP } & \text { pulmonary artery pressure } \\ \mathrm{CVP} & \text { central venous pressure } & \mathrm{ROSC} & \text { return of spontaneous circulation } \\ \mathrm{ECMO} & \text { extracorporeal membranous } & \mathrm{RV} & \text { right ventricle } \\ & \text { oxygenation } & \mathrm{SaO}_{2}, \mathrm{SvO}_{2}, \mathrm{StO}_{2} & \text { arterial/venous/tissue hemoglobin } \\ \mathrm{EtCO}_{2} & \text { end-tidal } \mathrm{CO}_{2} \text { concentration } & & \text { saturation } \\ \mathrm{MAP}^{\mathrm{m}} & \text { mean arterial pressure } & \mathrm{VF} & \text { ventricular fibrillation }\end{array}$

\section{References}

AO H, TANIMOTO H, YOSHITAKE A, MOON JK, TERASAKI H: Long-term mild hypothermia with extracorporeal lung and heart assist improves survival from prolonged cardiac arrest in dogs. Resuscitation 48: 163-174, 2001.

AVALLI L, MAGGIONI E, FORMICA F, REDAELLI G, MIGLIARI M, SCANZIANI M, CELOTTI S, COPPO A, CARUSO R, RISTAGNO G, FUMAGALLI R: Favourable survival of in-hospital compared to out-of-hospital refractory cardiac arrest patients treated with extracorporeal membrane oxygenation: an Italian tertiary care centre experience. Resuscitation 83: 579-583, 2012.

BĚLOHLÁVEK J, MLČEK M, HUPTYCH M, SVOBODA T, HAVRÁNEK S, OŠŤÁDAL P, BOUČEK T, KOVÁRNÍK T, MLEJNSKÝ F, MRÁZEK V, BĚLOHLÁVEK M, ASCHERMANN M, LINHART A, KITTNAR O: Coronary versus carotid blood flow and coronary perfusion pressure in a pig model of prolonged cardiac arrest treated by different modes of venoarterial ECMO and intraaortic balloon counterpulsation. Crit Care 16: R50, 2012.

FREDRIKSSON M, AUNE S, BANG A, THOREN AB, LINDQVIST J, KARLSSON T, HERLITZ J: Cardiac arrest outside and inside hospital in a community: mechanisms behind the differences in outcome and outcome in relation to time of arrest. Am Heart J 159: 749-756, 2010.

JANATA A, BAYEGAN K, STERZ F, WEIHS W, HOLZER M, SIPOS W, SPRINGLER G, BEHRINGER W: Limits of conventional therapies after prolonged normovolemic cardiac arrest in swine. Resuscitation 79: 133-138, 2008.

KAGAWA E, INOUE I, KAWAGOE T, ISHIHARA M, SHIMATANI Y, KURISU S, NAKAMA Y, DAI K, TAKAYUKI O, IKENAGA H, MORIMOTO Y, EJIRI K, ODA N: Assessment of outcomes and differences between in- and out-of-hospital cardiac arrest patients treated with cardiopulmonary resuscitation using extracorporeal life support. Resuscitation 81: 968-973, 2010.

LE GUEN M, NICOLAS-ROBIN A, CARREIRA S, RAUX M, LEPRINCE P, RIOU B, LANGERON O: Extracorporeal life support following out-of-hospital refractory cardiac arrest. Crit Care 15: R29, 2011.

LEBRETON G, POZZI M, LUYT CE, CHASTRE J, CARLI P, PAVIE A, LEPRINCE P, VIVIEN B: Out-of-hospital extra-corporeal life support implantation during refractory cardiac arrest in a half-marathon runner. Resuscitation 82: 1239-1242, 2011.

LIAKOPOULOS OJ, ALLEN BS, BUCKBERG GD, HRISTOV N, TAN Z, VILLABLANCA JP, TRUMMER G: Resuscitation after prolonged cardiac arrest: role of cardiopulmonary bypass and systemic hyperkalemia. Ann Thorac Surg 89: 1972-1979, 2010.

MADL C, HOLZER M: Brain function after resuscitation from cardiac arrest. Curr Opin Crit Care 10: 213-217, 2004.

MASSETTI M, TASLE M, LE PAGE O, DEREDEC R, BABATASI G, BUKLAS D, THUAUDET S, CHARBONNEAU P, HAMON M, GROLLIER G, GERARD JL, KHAYAT A: Back from irreversibility: extracorporeal life support for prolonged cardiac arrest. Ann Thorac Surg 79: 178-183, 2005.

NIEMANN JT, ROSBOROUGH JP, YOUNGQUIST S, THOMAS J, LEWIS RJ: Is all ventricular fibrillation the same? A comparison of ischemically induced with electrically induced ventricular fibrillation in a porcine cardiac arrest and resuscitation model. Crit Care Med 35: 1356-1361, 2007.

RISTAGNO G, TANG W, SUN S, WEIL MH: Spontaneous gasping produces carotid blood flow during untreated cardiac arrest. Resuscitation 75: 366-371, 2007. 
SAFAR P, ABRAMSON NS, ANGELOS M, CANTADORE R, LEONOV Y, LEVINE R, PRETTO E, REICH H, STERZ F, STEZOSKI SW ET AL.: Emergency cardiopulmonary bypass for resuscitation from prolonged cardiac arrest. Am J Emerg Med 8: 55-67, 1990.

SASSON C, ROGERS MA, DAHL J, KELLERMANN AL: Predictors of survival from out-of-hospital cardiac arrest: a systematic review and meta-analysis. Circ Cardiovasc Qual Outcomes 3: 63-81, 2010.

SIGL JC, CHAMOUN NG: An introduction to bispectral analysis for the electroencephalogram. J Clin Monit 10: $392-$ 404, 1994.

TRUMMER G, FOERSTER K, BUCKBERG GD, BENK C, HEILMANN C, MADER I, FEUERHAKE F, LIAKOPOULOS O, BREHM K, BEYERSDORF F: Successful resuscitation after prolonged periods of cardiac arrest: a new field in cardiac surgery. J Thorac Cardiovasc Surg 139: 1325-1332, 2010.

WEISFELDT ML, BECKER LB: Resuscitation after cardiac arrest: a 3-phase time-sensitive model. JAMA 288: 3035 $3038,2002$. 